\title{
Relationships between defecographic findings, rectal emptying, and colonic transit time in constipated patients
}

\author{
U Karlbom, L Påhlman, S Nilsson, W Graf
}

\begin{abstract}
The relations between defecographic findings, rectal emptying, and colonic transit time were analysed in 80 constipated patients (median age 49 years, range 22-87). Patients were classified into three clinically defined groups (slow transit, outlet obstruction, and a mixed group). Rectal evacuation was evaluated by computer-based area calculation. There were no differences in defecographic findings except that evacuation was less efficient in the slow transit group compared with the mixed group $(p<0.01)$ and with the outlet obstruction group $(p<0.05)$. Transit time was prolonged in the slow transit and mixed groups compared with the outlet group $(p<0 \cdot 001)$. Prominent impression of the puborectalis muscle during straining and the size of a rectocoele correlated with rectal emptying $(\mathbf{p}<0 \cdot 01)$. Perineal descent, anorectal angles, enterocoele, or intussusception were not significantly related to emptying. Prominent impression of the puborectalis muscle $(p<0.05)$ and impaired rectal emptying $(p<0.05)$ were more frequent in patients with prolonged transit time (six or more days). There was no significant correlation between transit time and rectal evacuation in the total study population. There was, however, an inverse relation between these variables $(r=-0.40, p<0.02)$ when all patients who claimed infrequent defecation (two or fewer/week) were analysed separately. These results did not confirm a direct relation between rectal evacuation and colonic transit time in constipated patients overall. The results are consistent with the suggestion that impaired colonic function may develop secondary to outlet obstruction in some patients.

(Gut 1995; 36: 907-912)
\end{abstract}

Keywords: constipation, defecography, rectal emptying, colonic transit time.

Departments Surgery and Radiology, University Hospital, Uppsala, Sweden

U Karlbom

U Pihlman

$S$ Nilsson

W Graf

Correspondence to: Dr U Karlbom, Departmen of Surgery, Akademiska Sjukhuset, S-751 85 Uppsala, Sweden.

Accepted for publication 7 October 1994 fewer stools per week or excessive straining at stool. ${ }^{1}$ These symptoms may be attributed to delayed colonic transit ${ }^{2}$ or impaired rectal emptying. ${ }^{3}$ The origin of the colonic motor defect is debatable. Histopathological changes in intramural nerve plexa compatible with nerve damage have been described in patients with longstanding constipation, 4 as have altered levels of neurotransmitters. ${ }^{5}$ It is not known, however, if these changes are primary or secondary to chronic use of laxatives.

Inhibition of small ${ }^{6}$ and large ${ }^{7}$ bowel transit has been observed after induced rectal stasis. These findings suggest that slow transit constipation may develop secondary to impaired rectal evacuation. This hypothesis is of special interest since impaired rectal emptying is sometimes associated with an inability to relax the puborectalis muscle during evacuation, ${ }^{8}$ a condition that may be treated with biofeedback training. ${ }^{9} 10$ Consequently, it may be argued that pelvic floor retraining, or indeed any therapeutic action aiming at improving rectal evacuation, should precede all other measures in slow transit constipation.

A close relationship between rectal evacuation and colonic transit time would favour a causual relation between these variables. The inter-relationships between structural defecographic findings, rectal emptying, and colonic transit time, however, have not been systematically studied. Such knowledge would help to define the potential benefit of therapeutic measures aiming at correcting morphological abnormalities and improving rectal emptying in the management of intractable constipation.

The aim of this study was to evaluate the relations between defecographic findings, rectal emptying, and the number of distribution of markers on colonic transit examinations overall and in separate clinically defined groups of constipated patients.

\section{Patients and methods}

Eighty patients ( 71 women, 9 men, median age 49 years, range 22-87) referred to the University Hospital, Uppsala for investigation of constipation of a median duration of 10 years (range 0.5-45) between January 1988 and June 1993 were included in this study. Patients with neurological illness were excluded. The stated bowel frequency ranged between one every three weeks and four per day (median two per week). The patients were classified into three groups depending on stool frequency, difficulties in rectal emptying, and general symptoms. The slow transit group $(n=10)$ consisted of patients with infrequent defecation (two or fewer/week) and abdominal pain or distension, or both. The group with outlet obstruction $(n=45)$ had normal stool frequency (more than two/week) but claimed evacuation difficulties. Patients with both infrequent defecation and evacuation difficulties were classified as mixed $(n=25)$. Clinical 
TABLE I Clinical characteristics of the three patient groups

\begin{tabular}{llll}
\hline & $\begin{array}{l}\text { Slow transit } \\
(n=10)\end{array}$ & $\begin{array}{l}\text { Mixed } \\
(n=25)\end{array}$ & $\begin{array}{l}\text { Outlet obstruction } \\
(n=45)\end{array}$ \\
\hline Age (y) & $43(23-66)$ & $46(22-82)$ & $52(31-87)$ \\
Male:female & $0: 10$ & $1: 24$ & $8: 37$ \\
Symptoms (y) & $15(2-30)$ & $12(0 \cdot 5-45)$ & $9(0 \cdot 5-36)$ \\
Stools/wk & $1(0 \cdot 35-2) \mathrm{tt \dagger}$ & $1(0 \cdot 5-2) \mathrm{t \dagger}$ & $7(2 \cdot 1-20)$ \\
Abdominal pain & 7 & $22 \mathrm{ft}$ & 26 \\
Abdominal distension & 5 & $18 \dagger$ & 20 \\
Digitation & $0^{\star} \ddagger$ & 13 & 17 \\
Motor stimulants/enemas & $8^{\star}$ & $21 \mathrm{t \dagger}$ & 19 \\
Abdominal surgery & 7 & 9 & 14 \\
Anal/transanal surgery & 1 & 5 & 9 \\
\hline
\end{tabular}

Values are median (range) or number of patients.

Abdominal surgery $=$ bowel and/or gynaecological surgery.

${ }^{\star} \mathrm{p}<0.05,{ }^{\star \star \star} \mathrm{p}<0.01$ (slow transit $v$ outlet obstruction); $+\mathrm{p}<0.05,+\mathrm{p}<0.01,++\mathrm{p}<0.001$

(mixed $v$ outlet obstruction); $\neq \mathrm{p}<0.05$ (slow transit $v$ mixed)

Kruskal Wallis and Mann-Whitney U test or Fischer's exact test.

characteristics of the patients are shown in Table I. Each patient underwent a colonic transit time examination and a defecography during the same investigation. No treatment was given between these examinations. The colonic width at the pelvic brim ranged between 2.8 and $5.9 \mathrm{~cm}$ in 34 patients whose double contrast enema was available for review, and in the remaining 46 patients the corresponding range was 2.7 to $5.5 \mathrm{~cm}$ on plain abdominal images thus ruling our megacolon in all patients. ${ }^{11}$

\section{DEFECOGRAPHY}

Oral contrast $(200 \mathrm{ml}$ liquid Mixobar Colon $0.5 \mathrm{~g} / \mathrm{ml}$, Astra Laboratories, Sweden) was given and one hour later $250 \mathrm{ml}$ semisolid barium paste (Mixobar Oesophagus $1 \mathrm{~g} / \mathrm{ml}$, Astra Laboratories) was instilled in the rectum. The patient was then seated on a commode, and after a short period of rest was instructed to squeeze, and then to strain and evacuate as completely as possible. Radiographs (lateral view) were taken during rest, squeezing, and straining. The whole investigation was documented on a videotape.

In measuring the anorectal angle, the axis of the anal canal and the posterior rectal wall was used. Perineal descent was defined as the position of the anorectal junction in relation to

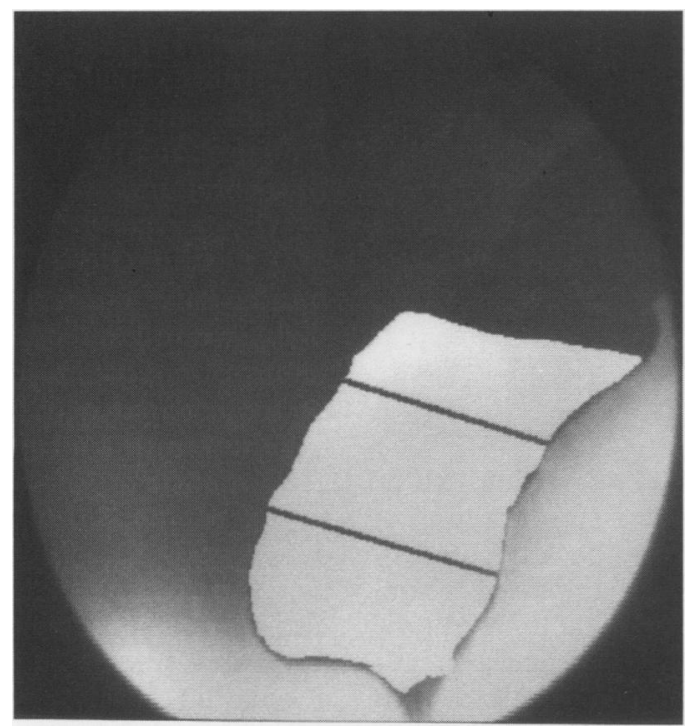

Figure 1: Distal $8 \mathrm{~cm}$ of rectum at rest. The boundaries of homogenous contrast is outlined. tuber os ischi at straining as compared with rest. The size of a rectocoele was calculated during straining as the distance from the apex of the anterior rectal wall to a line drawn in the axis of the anal canal. The presence of an enterocoele and its relation to the rectum was noted. Circumferential intussusception was graded in four groups: $\leqslant 6 \mathrm{~mm},>6 \mathrm{~mm}$ but not reaching the anal canal, intra-anal, and external prolapse. A prominent impression of the puborectalis muscle during straining was judged as a sign of a paradoxical puborectalis contraction. All figures presented in the results section are corrected for a magnification factor of 1.7 noted by incorporating a lead marker at the centre of the commode.

Rectal evacuation on coded videotapes was evaluated by computer based area calculation. An image from the videotape was transferred to a computer with an analogue/digital converter (Matrox, type VIP 1024) and processed with the Epsilon system (IMTEC, Uppsala, Sweden) consisting of an array processor, a display processor, and $4 \mathrm{Mb}$ image memory. The host computer was a Motorola 68030 with a $300 \mathrm{Mb}$ data and program disc. Images from the resting phase, after first strain and the postevacuation phase was selected for analysis. The boundaries of homogenous contrast was outlined manually - that is, a thin layer of contrast covering the mucosa was not included in the region of interest. The area of the distal $8 \mathrm{~cm}$ of the rectum was calculated at rest (Fig 1), after first strain, and after the total evacuation period (Fig 2). The time used for the first strain (that is, maximum evacuation) as well as the total evacuation time was noted. Rectal evacuation was expressed as the percentage evacuated area, percentage evacuated area per second during maximum evacuation, and percentage evacuated area per second during the total straining period (Fig 3). This was a modification of the method described by Turnbull et al. ${ }^{12}$

The three evacuation parameters were reproducible as evaluated by the method described by Bland and Altman ${ }^{13}$ in 20 unselected

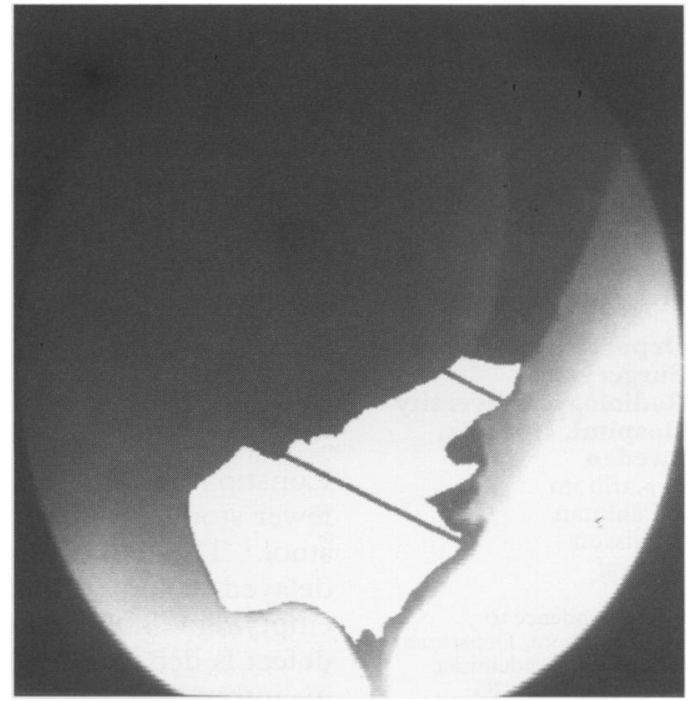

Figure 2: The same region as shown in Figure 1 after repeated attempts of evacuation. Note that the area with homogenous contrast has diminished. 


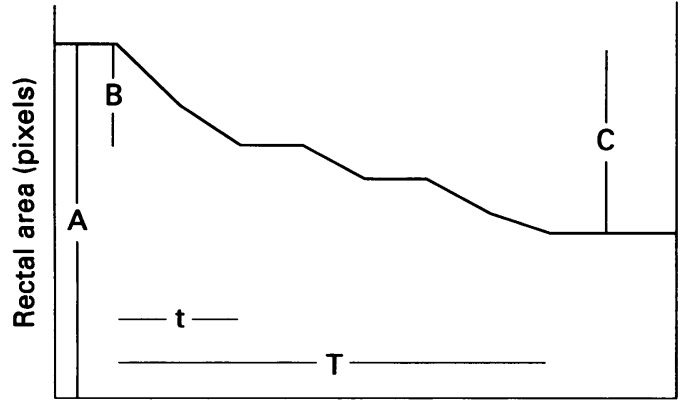

Time (s)

Figure 3: Graphical representation of the percentage decrease in rectal area $C / A$, the rate of emptying during maximum evacuation $B / A(t)$ and the rate of emptying during the total emptying period $C / A(T)$.

subjects. The reproducibility of the percentage evacuated area per second during the total evacuation period is shown in Figure 4. The reproducibility of the other evacuation parameters was of a similar magnitude (date not shown). In order to validate further the method, a subjective grading was done independently by three investigators $(1=$ complete evacuation, 2 =intermediate, and 3 =poor). There were good correlations between the subjective grading and the area calculation methods $(r=0.51-0.66, p<0.001)$. All defecographic evaluations were performed without knowledge of the clinical characteristics or the results of the transit examination.

\section{COLONIC TRANSIT TIME}

The patients ingested 10 radiopaque ringmarkers (diameter $3 \mathrm{~mm}$ ) daily at noon for six days. On day seven, 24 hours after the last intake of markers, a plain abdominal $x$ ray was taken. Except for the fact that no rod markers were used, this was the same method as described by Abrahamsson et al. ${ }^{14}$ No stool softeners, laxatives, or enemas were allowed during the investigation. The $x$ ray films were analysed with regard to the total number of retained markers and their distribution. The gastrointestinal transit time (=colonic transit time) was calculated as previously described. ${ }^{14}$ With this method, the median transit time for healthy men is 1.8 days (upper 95th centile $2 \cdot 8$ days) and for healthy women $2 \cdot 8$ days

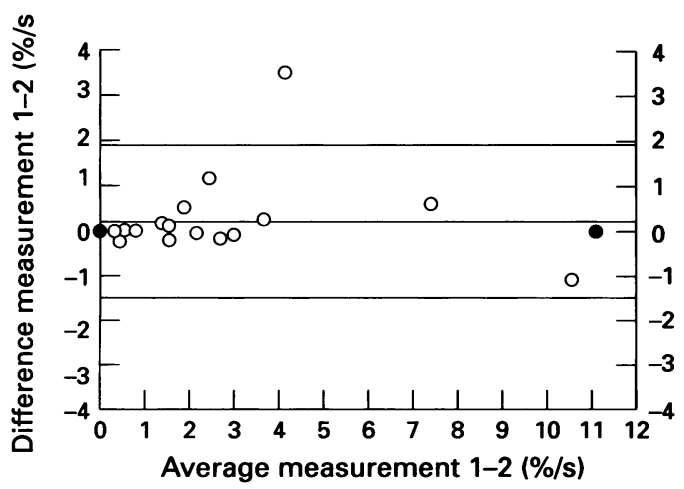

Figure 4: Reproducibility of rectal evacuation measurements (percentage evacuated/second during the total evacuation period) in 20 subjects. The difference between the measurements is plotted against their mean. The horizontal lines indicate the mean (2SD). The filled circles represent two paired measurements. (upper 95th centile $4 \cdot 7$ days). For analysis of the segmental distribution of markers, the colon was divided into four main segments by lines drawn from the centre of the promontory. Markers situated between lines through the right pelvic outlet and through the middle of the vertebral column were considered to reside in the right colon. Markers between lines through the vertebral column and to the left iliac crest were regarded as located in the left colon. Those situated between lines through the left iliac crest and the centre of the left femoral head were judged as belonging to the sigmoid colon. Finally, markers between lines through the right pelvic outlet and the centre of left femoral head were considered as being in the rectum. This method has previously been used for assessing regional colonic transit. ${ }^{15}$

\section{STATISTICAL ANALYSES}

Values are expressed as median (range) unless otherwise stated. Correlations were studied with the Spearman rank correlation test and expressed as an $r$ coefficient and a $p$ value. Kruskal Wallis and Mann-Whitney $U$ test were used for comparisons between groups. Fisher's exact test was used to compare proportions. All $p$ values are two tailed.

\section{Results}

RADIOLOGICAL FINDINGS

Some degree of intussusception was observed in 51 of 71 women (72\%) and in four of nine men $(44 \%, p>0.20)$. The infolding was $6 \mathrm{~mm}$ or less in 11 patients, $>6 \mathrm{~mm}$ but not reaching the anal canal in 39, intra-anal in four, and one patient had external prolapse. An enterocoele was noted in 37 of 71 women (52\%), and two of nine men $(22 \%, p>0 \cdot 10)$. The enterocoele was situated adjacent to the rectum during straining in nine cases. A rectocoele exceeding $2 \mathrm{~cm}$ was observed in 43 of the women (61\%) but in none of the men $(p<0.01)$. In 38 of the rectocoeles, entrapment of contrast at the end of straining was noted. The rectocoele was larger in those with entrapment (median $2.7 \mathrm{~cm}$, range $1.5-4.4$ ) than in those with to those without (median $1.2 \mathrm{~cm}$, range $0-2 \cdot 7$, $\mathrm{p}<0.001$ ). Prominent impression of the puborectalis muscle during straining was seen in seven women (10\%) and four men (44\%, $\mathrm{p}<0.05)$. Six patients had a decreased anorectal angle during straining compared with at rest. The median evacuated area during the total emptying period was $88 \%$ (range $0-100$ ). The median rate of evacuation was $2 \cdot 1 \%$ per second (0-20) during the total period and $4.0 \%$ per second $(0-20)$ during maximum evacuation. For each emptying variable, men had slightly more efficient evacuation than women, but this difference was not statistically significant (data not shown).

The colonic transit time was faster in men (median 2.1 days, range 1.4-5.9) than in women (median 3.9 days, range $0.7-6.5$, $\mathrm{p}<0.05$ ). Fifty patients had a normal transit time - that is, within the 95 th centile for each 
TABLE II Results of colonic transit and defecographic examinations in relation to clinical classification. Values are median (range) or number of patients.

\begin{tabular}{|c|c|c|c|}
\hline & $\begin{array}{l}\text { Slow transit } \\
(n=10)\end{array}$ & $\begin{array}{l}\text { Mixed } \\
(n=25)\end{array}$ & $\begin{array}{l}\text { Outlet obstruction } \\
(n=45)\end{array}$ \\
\hline $\begin{array}{l}\text { Colonic transit time: } \\
\text { Transit time (d) } \\
\text { \% Right colon } \\
\text { \% Left colon } \\
\text { \% Rectosigmoid }\end{array}$ & $\begin{array}{l}6 \cdot 0(3 \cdot 9-6 \cdot 4)^{\star \star \star} \\
32(22-67) \\
29(14-53) \\
28(9-55)\end{array}$ & $\begin{array}{l}5 \cdot 2(0 \cdot 7-6 \cdot 5) \mathrm{tt \dagger} \\
40(0-92) \\
33(0-63)^{\star} \\
23(0-58)+\dagger\end{array}$ & $\begin{array}{l}2 \cdot 5(0 \cdot 8-6 \cdot 0) \\
27(0-75) \\
21(0-94) \\
45(0-100)\end{array}$ \\
\hline $\begin{array}{l}\text { Defecography: } \\
\text { PIP } \\
\text { ARA strain-rest } \\
\text { Perineal descent }(\mathrm{cm}) \\
\text { Rectocoele }(\mathrm{cm}) \\
\text { Intussusception } \\
\text { Entercoele } \\
\% \text { Evacuated } \\
\% \text { Evacuated } / \mathrm{s}_{\text {tot }} \\
\% \text { Evacuated } / \mathrm{s}_{\max }\end{array}$ & $\begin{array}{l}1 \\
28(0-48) \\
2 \cdot 6(1 \cdot 8-3 \cdot 5) \\
2 \cdot 4(0 \cdot 5-3 \cdot 3) \\
7 \\
5 \\
70(26-100) \\
1 \cdot 6(0 \cdot 5-3 \cdot 6) \\
1 \cdot 6(0-5 \cdot 2)^{\star} \neq \ddagger\end{array}$ & $\begin{array}{l}4 \\
28(-8-59) \\
2 \cdot 6(0 \cdot 7-4 \cdot 6) \\
2 \cdot 4(0-4 \cdot 4) \\
16 \\
11 \\
81(27-100) \\
2 \cdot 1(0 \cdot 6-8 \cdot 3) \\
4 \cdot 3(0 \cdot 6-8 \cdot 3)\end{array}$ & $\begin{array}{l}6 \\
25(-17-62) \\
2 \cdot 2(-0 \cdot 4-5 \cdot 5) \\
1 \cdot 8(0-3 \cdot 6) \\
32 \\
23 \\
95(0-100) \\
2 \cdot 2(0-20 \cdot 0) \\
4 \cdot 1(0-20 \cdot 0)\end{array}$ \\
\hline
\end{tabular}

$\mathrm{ARA}=$ anorectal angle, $\mathrm{PIP}=$ prominent impression of the puborectalis muscle during straining, $\%$ evacuated $/ s_{\text {tot }}=\%$ evacuated per second during the total evacuation period, $\%$ evacuated $/ s_{\max }=\%$ evacuated per second during maximum evacuation.

${ }^{\star} \mathrm{p}<0.05,{ }^{\star \star \star}{ }^{\star} \mathrm{p}<0.001$ (slow transit $v$ outlet obstruction); $+\mathrm{p}<0.05, \mathrm{t}+\mathrm{p}<0.01,+t+\mathrm{p}<0.001$ (mixed $v$ outlet obstruction); $\neq \neq \mathrm{p}<0 \cdot 01$ (slow transit $v$ mixed).

Kruskal Wallis and Mann-Whitney U test or Fischer's exact test.

TABLE III Defecographic findings in patients according to transit time

\begin{tabular}{lcc}
\hline & $\begin{array}{l}\text { Transit } \geqslant 6 d \\
(n=14)\end{array}$ & $\begin{array}{l}\text { Transit }<6 d \\
(n=66)\end{array}$ \\
\hline PIP & $5(36)^{\star}$ & $6(9)$ \\
ARA strain-rest & $18(-8-39)^{\star}$ & $26(-17-62)$ \\
Perineal descent $(\mathrm{cm})$ & $2 \cdot 4(0 \cdot 7-3 \cdot 8)$ & $2 \cdot 5(-0 \cdot 4-5 \cdot 5)$ \\
Rectocoele $(\mathrm{cm})$ & $2 \cdot 5(0-4 \cdot 4)$ & $2 \cdot 1(0-3 \cdot 8)$ \\
Intussusception & $9(64)$ & $46(70)$ \\
Enterocoele & $7(50)$ & $32(49)$ \\
$\%$ Evacuated & $51(26-100)^{\star}$ & $94(0-100)$ \\
$\%$ Evacuated/s & $1 \cdot 4(0-10)^{\star}$ & $2 \cdot 3(0-20)$ \\
$\%$ Evacuated/s & $1 \cdot 7(0-10)^{\star}$ & $4 \cdot 3(0-20)$ \\
\hline
\end{tabular}

Values are median and range or number of patients and percentages. $\mathrm{PIP}=$ prominent impression of the puborectalis muscle during straining. ARA = anorectal angle.

$\%$ evacuated $/ \mathrm{s}_{\text {tot }}=\%$ evacuated per second during the total evacuation period, $\%$ evacuated $/ \mathrm{s}_{\max }=\%$ evacuated per second during maximum evacuation.

${ }^{\star} \mathrm{p}<0 \cdot 05$, Mann-Whitney U test or Fischer's exact test.

sex. Among the 30 patients (28 women, two men) with transit time above the 95th centile, were 14 women with a transit time $\geqslant 6$ days (more than $90 \%$ of the markers retained).

\section{RADIOLOGICAL FINDINGS IN RELATION TO} CLINICAL CLASSIFICATION

The frequency of intussusception, enterocoele, and paradoxical puborectalis contraction did not differ between the three patient groups. Neither did perineal descent nor change in anorectal angle (strain-rest) differ between the groups. There was a tendency towards larger rectocoeles in the slow transit and mixed group compared with the outlet group ( $\mathrm{p}=0.09$, and $\mathrm{p}=0.06$, respectively). Evacuation was less efficient in the slow transit group and there was

TABLE IV Correlations between colonic transit time and rectal emptying in the three separate patient groups (Spearman rank correlation test)

\begin{tabular}{|c|c|c|c|}
\hline & $\begin{array}{l}\text { Slow transit } \\
(n=10)\end{array}$ & $\begin{array}{l}\text { Mixed } \\
(n=25)\end{array}$ & $\begin{array}{l}\text { Outlet obstruction } \\
(n=45)\end{array}$ \\
\hline $\begin{array}{l}\text { Transit time: } \\
\% \text { Evacuated } \\
\% \text { Evacuated } / \mathrm{s}_{\text {tot }} \\
\% \text { Evacuated } / \mathrm{s}_{\max }\end{array}$ & $\begin{array}{l}r=-0.45, p=0.19 \\
r=-0.20, p=0.58 \\
r=-0.49, p=0.14\end{array}$ & $\begin{array}{l}\mathrm{r}=-0.13, \mathrm{p}=0.53 \\
\mathrm{r}=-0.34, \mathrm{p}=0.09 \\
\mathrm{r}=-0.12, \mathrm{p}=0.56\end{array}$ & $\begin{array}{l}\mathrm{r}=-0.14, \mathrm{p}=0.37 \\
\mathrm{r}=-0.15, \mathrm{p}=0.31 \\
\mathrm{r}=-0.15, \mathrm{p}=0.32\end{array}$ \\
\hline $\begin{array}{l}\text { \% In rectosigmoid: } \\
\% \text { Evacuated } \\
\% \text { Evacuated } / \mathrm{s}_{\text {tot }} \\
\% \text { Evacuated } / \mathrm{s}_{\max }\end{array}$ & $\begin{array}{l}r=-0.55, p=0.10 \\
r=-0.04, p=0.90 \\
r=-0.36, p=0.30\end{array}$ & $\begin{array}{l}\mathrm{r}=-0.39, \mathrm{p}=0.05 \\
\mathrm{r}=-0.54, \mathrm{p}=0.005 \\
\mathrm{r}=-0.45, \mathrm{p}=0.02\end{array}$ & $\begin{array}{l}r=-0.07, p=0.66 \\
r=-0.13, p=0.38 \\
r=-0.24, p=0.10\end{array}$ \\
\hline
\end{tabular}

$\%$ evacuated $/ \mathrm{s}_{\mathrm{tor}}=\%$ evacuated per second during the total evacuation period,

$\%$ evacuated $/ \mathrm{s}_{\max }=\%$ evacuated per second during maximum evacuation. a significant difference regarding maximum evacuation per second (Table II).

The colonic transit time was prolonged in the slow transit and mixed group compared with the outlet obstruction group $(p<0.001)$. There was also a difference in the distribution of markers between the slow transit, mixed, and outlet obstruction groups. In the former two groups most markers were retained in the right colon whereas in the outlet obstruction group the majority of markers were in the rectosigmoid segment (Table II).

When separate symptoms such as abdominal pain and distension were analysed in relation to radiological findings, no difference was found between asymptomatic and symptomatic patients, except that digitation was associated with large rectocoeles $(p<0.05)$ and absence of the paradoxical puborectalis contraction $(\mathrm{p}<0.01)$.

\section{CORRELATIONS}

The size of a rectocoele correlated with the percentage evacuated area $(r=-0.45$, $p<0.001$ ), the rate of emptying during the total evacuation period $(\mathrm{r}=-0.32, \mathrm{p}<0.01)$, and the rate of emptying during maximum evacuation $(r=-0.33, p<0.01)$. Patients with prominent puborectalis sign evacuated less contrast than those without this sign (median $46 \%$, range $0-100 v 79 \%$, range $17-100$, $\mathrm{p}<0.004)$. Furthermore, the rate of emptying was lower in this group both during the total evacuation period (median $0.9 \%$ per second, range $0-5 v$ median $2 \cdot 3 \%$ per second, range $0.3-20, \mathrm{p}<0.01$ ), and during maximum evacuation (median $1.9 \%$ per second, range $0-6.5 v 4.3 \%$ per second, range $0-20$, $\mathrm{p}<0.01)$. Neither intussusception, enterocoele, perineal descent, nor change in anorectal angle were significantly correlated to any of the emptying variables (data not shown).

There were no significant associations between transit time and intussusception, enterocoele, or rectocoele. The colonic transit time did not correlate with rectal emptying in the total population either when measured as the percentage evacuated area $(r=-0.06$, $p>0.60$ ), or when measured as the percentage per second during the whole evacuation period $(\mathrm{r}=-0.09, \mathrm{p}>0.40)$ or during maximum evacuation $(\mathrm{r}=-0.12, \mathrm{p}>0.20)$. The proportion of markers in the rectosigmoid segment correlated to the rate of emptying during maximum evacuation $(\mathrm{r}=-0.30, \mathrm{p}<0.01)$. When patients with a transit time of six days or more were compared with those with a transit time less than six days, it was found that defecographic abnormalities consistent with paradoxical puborectalis contraction and poor emptying were more frequent in the former group (Table III). Moreover, 10 of 14 (71\%) patients with a colonic transit time of six days or more exhibited poor rectal emptying associated with either a rectocoele with entrapment of contrast or a prominent impression of the puborectalis muscle during straining.

The above mentioned correlations between transit time, rectal emptying, and 
defecographic findings were also analysed separately in each patient group. In the mixed group there was a correlation between the proportion of transit markers in the rectosigmoid segment and all evacuation parameters (Table IV). The association between the size of a rectocoele, prominent puborectalis sign, and evacuation was also seen in the groups. No other significant correlation was found. However, when patients who stated a defecation frequency of twice or less per week (slow transit and mixed group) were analysed together, an inverse relation was observed between colonic transit time and the rate of emptying during the total evacuation period $(\mathrm{r}=-0.40, \mathrm{p}<0.02)$.

\section{Discussion}

The relationships between morphological abnormalities, rectal emptying, and colonic transit are of theoretical interest in the interpretation of the pathophysiology of severe constipation. In addition, this question has practical consequences in the clinical management of patients. If delayed colonic transit is secondary to outlet obstruction, the logical treatment would be measures aiming at improving rectal emptying. If, on the other hand, no such relation exists, these measures would be useless, and just a waste of resources and time. It has previously been claimed that paradoxical puborectalis contraction plays an important role in the genesis of slow transit constipation. ${ }^{1617}$ The former condition has been successfully treated with biofeedback. ${ }^{9} 10$

There was a good agreement between the clinical classification and the colonic transit time. In contrast, there was a poor correlation between a sense of obstruction and rectal evacuation as evaluated by defecography. Patients who claimed emptying difficulties actually had the most efficient evacuation. In the outlet obstruction group, 41 of 45 had intussusception or enterocoele, or both, and theoretically, these findings could give a sensation of incomplete emptying. These findings were equally common in the slow transit group, but without causing a sense of obstruction. This may be due to an impaired rectal sensibility in the slow transit group. ${ }^{18}$

The present study showed that a rectocoele is associated with impaired rectal emptying. This relation is not necessarily causual since intense straining may result in an enlarged ventral rectal 'outpocketing'. Another finding was that a prominent impression of the puborectalis muscle during straining was related to less efficient rectal emptying. The influence of a rectocoele and paradoxical puborectalis contraction on emptying is controversial. A recent study found such a relationship, ${ }^{19}$ whereas it was not observed in another. ${ }^{20}$ Our results support the former study and suggest that these variables affect emptying. On the other hand, rectal intussusception did not seem to hamper emptying. This finding is in agreement with the disappointing symptomatic results of surgery for rectal intussusception. ${ }^{2122} \mathrm{We}$ could not confirm the results of Pezim et al who recently reported that a perineal descent of $1 \mathrm{~cm}$ or less was associated with impaired rectal emptying. ${ }^{23}$

Although no direct relationship between rectal emptying and colonic transit time (overall or in the separate patient groups) was verified in this study, we did find such a relation when the analysis was restricted to patients with infrequent defecation. A causual relationship between rectal emptying and colonic transit is impossible to establish from the present study. Nevertheless, our findings are consistent with that impaired rectal emptying may eventually lead to colonic dysfunction in some patients. This is also in agreement with the frequent finding of paradoxical contraction of the puborectalis muscle and impaired emptying in patients with transit time of six days or more. Actually, 10 of $14(71 \%)$ in this group had signs of outlet obstruction. The predominating abnormality was a rectocoele with entrapment of contrast at attempted defecation (five cases). An isolated impression of the puborectalis muscle during straining was seen in two cases whereas a combination of these findings was observed in three cases. It has previously been claimed that pelvic floor retraining is indicated in many patients with slow colonic transit. ${ }^{1617}$ Our results suggest that some of these patients also have evacuation problems due to a rectocoele with incomplete emptying.

We observed an interesting difference according to gender. It was hardly surprising that rectocoeles were only observed in women. The predominance of men with paradoxical puborectalis contraction in this population suggests that this disorder may be proportionally more frequent in men with constipation.

In summary, the stated defecation frequency corresponded to the colonic transit time whereas a sensation of obstructed defecation did not relate to rectal evacuation as evaluated by defecography. The size of a rectocoele and prominent impression of the puborectalis muscle was correlated to rectal emptying. Rectal emptying was not directly related to colonic transit time in the total population. A separate analysis of patients with infrequent defecation revealed an inverse relation between the rate of rectal emptying and colonic transit time. A paradoxical puborectalis contraction and poor rectal emptying were more common in those with prolonged as compared with those with normal colonic transit. These results indicate a possibility for the development of slow colonic transit secondary to outlet obstruction in some patients.

Part of this study has been presented at the International Society of University Colon and Rectal Surgeons Congress in Singapore July 1994.

1 Drossman DA, Sandler RS, McKee DC, Lovitz AJ. Bowel patterns among subjects not seeking health care. Gastroenterology 1982; 83: 529-34.

2 Preston DM, Lennard-Jones JE. Severe chronic constipation of young women: 'idiopathic slow transit constipation'. Gut 1986; 27: 41-8.

3 Barnes PRH, Lennard-Jones JE. Balloon expulsion from the rectum in constipation of different types. Gut 1985; 26: 1049-52.

4 Krishnamurthy S, Schuffler MD, Rohrmann CA, Pope CE. 
Severe idiopathic constipation is associated with a distinctive abnormality of the colonic myenteric plexus. Gastroenterology 1985; 88: 26-34.

5 Koch TR, Carnley JA, Go L, Go VLW. Idiopathic chronic constipation is associated with decreased colonic vasoactive intestinal polypeptide. Gastroenterology 1988; 94: 300-10.

6 Youle MS, Read NW. Effect of painless rectal distension on gastrointestinal transit of solid meal. Dig Dis Sci 1984; 29: $902-6$.

7 Klauser AG, Voderholzer WA, Heinrich CA, Schindlebeck NE, Muller-Lissner SA. Behavioral modification of colonic function. Can constipation be learned? Dig Dis $\mathrm{Sci}$ 1990; 35: 1271-5.

8 Preston DM, Lennard-Jones JE. Anismus in chronic constipation. Dig Dis Sci 1985; 30: 413-8.

9 Kawimbe BM, Papachrysostomou M, Binnie NR, Clare N, Smith AN. Outlet obstruction constipation managed by biofeedback. Gut 1991; 32: 1175-9.

10 Papachrysostomou M, Smith AN. Effects of biofeedback on obstructed defecation - reconditioning of the defecation reflex? Gut 1994; 35: 252-6.

11 Preston DM, Lennard-Jones JE, Thomas BM. Towards a radiologic definition of megacolon. Gastrointest Radiol 1985; 10: 167-9.

12 Turnbull GK, Bartram CI, Lennard-Jones JE. Radiologic studies of rectal evacuation in adults with idiopathic constudies of rectal evacuation in adults with idiopathic con-
stipation. Dis Colon Rectum 1988; 31: 190-7.

13 Bland JM, Altman DG. Statistical methods for assessing agreement between two methods of clinical measurement. Lancet 1986; i: 307-10.

14 Abrahamsson $\mathrm{H}$, Antov S, Bosaeus I. Gastrointestinal and colonic segmental transit time evaluated by a single abdominal $\mathrm{x}$-ray in healthy subjects and constipated patients. Scand f Gastroenterol 1988; 23 (suppl 152): 72-80.

15 Martelli H, Devroede G, Arhan P, Duguay C. Mechanisms of idiopathic constipation: outlet obstruction. Gastroenterology 1978; 75: 623-31.

16 Kuijpers HC, Bleijenberg G, Morree $H$. The spastic pelvic floor syndrome. Large bowel obstruction caused by pelvic floor dysfunction: a radiological study. Int $\mathcal{f}$ Colorect Dis 1986; 1: 44-8.

17 Kuijpers HC. Application of the colorectal laboratory in diagnosis and treatment of functional constipation. Dis Colon Rectum 1990; 33: 35-9.

18 Åkervall S, Fasth S, Nordgren S, Öresland T, Hultén $\mathrm{L}$ The functional results after colectomy and ileorectal anastomosis for severe constipation (Arbuthnot Lane's anastomosis for severe constipation (Arbuthnot Lane's disease) as related to
Dis 1988; 3: $96-101$.

19 Siproudhis L, Dautreme S, Ropert A, Bretagne JF, Heresbach D, Raoul JL, et al. Dyschezia and rectocele - a marriage of convenience? Dis Colon Rectum 1993; 36: 1030-6.

20 Nielsen MB, Buron B, Christiansen J, Hegedus V. Defecographic findings in patients with anal incontinence and constipation and their relation to rectal emptying. Dis Colon Rectum 1993; 36: 806-9.

21 McCue JL, Thomson JPS. Rectopexy for internal rectal intussusception. Br f Surg 1990; 77: 632-4.

22 Christiansen J, Zhu BW, Rasmussen OÖ, Sörensen M Internal rectal intussusception: Results of surgical repair. Dis Colon Rectum 1992; 35: 1026-9.

23 Pezim ME, Pemberton JH, Levin KE, Litchy WJ, Phillips SF. Parameters of anorectal and colonic motility in health and severe constipation. Dis Colon Rectum 1993; 36: 484-91. 